\title{
Sistem Penentuan Perhitungan Jumlah Produksi Folding Gate Menggunakan Fuzzy Logic Pada PT. Jihan Jaya
}

\author{
Laily Oktaviani ${ }^{1}$ \\ ${ }^{1}$ Program Studi Informasi, Fakultas Teknologi Informasi- Universitas Serang Raya \\ Jl. Raya Cilegon - Serang Km.5 Taman Drangong Kota serang - Banten, indonesia \\ ${ }^{1}$ Lailylely.llegmail.com
}

\begin{abstract}
Permintaan pasar yang semakin banyak dengan menggunakan bahan baku besi jenis galvanis sedang di minati oleh masyarakat sebab bahan yang digunakan adalah anti karat dan lebih awet dibandingkan bahan besi galvanis. Karena banyaknya permintaan masyarakat sebuah badan usaha kerap kali mengalami kesulitan dalam perhitungan jumlah produksi yang dilakukan oleh perusahaan, sehingga tiadak ada data yang valid untuk mengetahui jumlah produksi folding gate ini. Dengan adanya masalah ini maka dilakukan penelitian tentang penentuan jumlah produksi barang folding gate menggunakan fuzzy logic, khususnya pada PT. Jihan Jaya. Sistem ini akan membantu pihak perusahaan dalam menghitung atau meninjau sejauh mana perusahaan dapat memproduksi folding gate dalam tempo 1 (satu) tahun yang berdampak baik bagi peningkatan produksi pada perusahaan PT. Jihan Jaya. Penggunakan metode fuzzy logic akan dilakukan dengan tahap-tahap (a)pembentukan himpunan fuzzy, (b)aplikasi fungsi implikasi, (c)membentuk aturan-aturan, (d)penegasan (defuzzifikasi). Model Inferensi yang digunakan yaitu model Tsukamoto. Dari hasil penelitian ini akan diketahui jumlah produksi yang akurat..
\end{abstract}

Kata kunci: Sistem Penentuan, Fuzzy Logic, dan Model Inferensi.

\section{LATAR BELAKANG}

Industri kontruksi kadang mengalami kesulitan untuk menentukan jumlah produksi yang akan diproduksi oleh

perusahaan. Dengan cara yang belum jelas perhitungannya, menimbulkan perhitungan tidak akurat. Karena itulah akan dibahas mengenai penentuan perhitungan jumlah produksi folding gate menggunakan fuzzy logic pada PT. Jihan Jaya, sehingga membantu pihak perusahaan dalam membuat keputusan dalam penentuan jumlah folding gate yang akan diproduksi. Perancangan Sistem ini menggunakan notasi dari Unified Modelling Language (UML).

\section{DASAR TEORI}

\section{A. Unified Modelling Language (UML)}

Menurut Munawar mengatakan UML adalah "salah satu alat bantu yang sangat handal di dunia pengembangan sistem yang berorientasi objek".[5] s keputusan (X) ke suatu skala yang dapat diperbandingkan dengan semua rating alternatif yang ada.

\section{B. Fuzzy Logic}

Fuzzy logic (logika fuzzy) adalah salah satu komponen pembentuk soft computing. Dasar logika fuzzy adalah himpunan fuzzy. Logika fuzzy (fuzzy logic) dapat dianggap sebagai kotak hitam yang menghubungkan antara ruang input menuju ke ruang output. Kotak hitam tersebut berisi cara atau metode yang dapat digambarkan untuk mengolah dat input menjadi output dalam bentuk informasi yang baik[5].

\section{FIS Tsukamoto}

Motode Tsukamoto merupakan perluasan dari penalaran monoton, setiap konsekuen pada aturan yang berbentuk IF-Then harus dipresentasikan dengan suatu himpunan fuzzy dengan fungsi keanggotaan yang monoton. Sebagai hasilnya, output hasil inferensi dari tiap-tiap aturan diberikan secara tegas (crips) berdasarkan $\alpha$-predikat (file strength). Dari hasil akhir diperoleh dengan menggunakan rata-rata terbobot. Untuk mendapatkan Output, diperlukan 4 tahapan :

a. Himpunan fuzzy. Langkah pertama dalam proses fuzzifikasi yaitu menetukan variabel fuzzy dan himpunan fuzzynya. Lalu derajat keanggotaan antara data masukan fuzzy dengan himpunan fuzzy yang telah didefinisikan untuk setiap variabel masukan sistem dari setiap aturan fuzzy.

b. Aplikasi Fungsi Implikasi pada metode tsukamoto. Tiap-tiap aturan (komposisi) pada basis pengetahuan fuzzy akan berhubungan dengan suatu relasi fuzzy. Bentuk umum dari aturan yang digunakan dalam fungsi implikasi ini adalah :

IF $\mathrm{x}$ is $\mathrm{A}$ THEN $\mathrm{y}$ is $\mathrm{B}$

c. Penalaran monoton. Penalaran secara monoton digunakan sebagai digunakan sebagai dasar untuk teknik implikasi fuzzy. Jika 2 daerah fuzzy direlasikan dengan implikasi sederhana yaitu :

IF $x$ is $A$ THEN $y$ is $B$

Transfer fungsi

$$
y=f((x, A), B)
$$

d. Defuzzifikasi. Input dari proses defuzzifikasi adalah suatu himpunan fuzzy yang diperoleh dari komposisi aturan-aturan fuzzy, sedangkan output dihasilkan 
merupakan suatu bilangan pada domain himpunan fuzzy

tersebut.[5]

\section{ANALISIS DAN PERANCANGAN SISTEM}

Analisis pendukung keputusan dilakukan untuk menentukan jumlah produksi folding gate. Data yang diperoleh berdasarkan jumlah permintaan, persediaan dan jumlah produksi yang telah ada, yaitu :

\begin{tabular}{|c|c|c|c|c|}
\hline No & Bulan & Pemesanan & Persediann & $\begin{array}{l}\text { Jumblah } \\
\text { Produ bst }\end{array}$ \\
\hline 1 & 03 spoil 2014 & 60 & 45 & 105 \\
\hline 2 & 10 spoil 2064 & 55 & 43 & 98 \\
\hline 3 & 15 A poril 2004 & 51 & 55 & 106 \\
\hline 4 & 24 Apoil 2014 & 65 & 50 & 115 \\
\hline 5 & 30 spril 2004 & 62 & 54 & 116 \\
\hline 6 & $06 \mathrm{Mei} 2014$ & 60 & 65 & 125 \\
\hline 7 & $14 \mathrm{Mei} 2014$ & 65 & 67 & 132 \\
\hline 8 & $20 \mathrm{Mei} 2014$ & 70 & 65 & 135 \\
\hline 9 & $28 \mathrm{Mei} 2014$ & 55 & 53 & 108 \\
\hline 10 & 04 Juni 2014 & 55 & 51 & 106 \\
\hline 11 & O9 Juni 2014 & 65 & 65 & 130 \\
\hline 12 & 16 Jumi 2014 & 61 & 55 & 116 \\
\hline
\end{tabular}

Tabel 1. Tabel Variabel dan Semesta Pembicaraan

\begin{tabular}{|c|c|c|c|c|}
\hline No & Fungar & $\begin{array}{c}\text { Nama } \\
\text { Variabel }\end{array}$ & $\begin{array}{c}\text { Semssta } \\
\text { Pembicaraan }\end{array}$ & Keterangan \\
\hline \multirow[t]{2}{*}{1} & \multirow{2}{*}{ Inpean } & Perminanin & [51- & 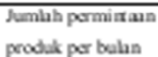 \\
\hline & & Pensediun & {$[43-67]$} & $\begin{array}{l}\text { Jumlih persedian } \\
\text { produl por belan }\end{array}$ \\
\hline 2 & Ouspas & $\begin{array}{l}\text { Jumlì } \\
\text { poodulsisi }\end{array}$ & {$[98-135]$} & $\begin{array}{l}\text { Kapashias jumlah } \\
\text { produlsisi per belhn }\end{array}$ \\
\hline
\end{tabular}

Tabel 2. Tabel Himpunan Fuzzy

\begin{tabular}{|c|c|c|c|c|c|}
\hline No & Fungri & $\begin{array}{c}\text { Nama } \\
\text { Variabel }\end{array}$ & $\begin{array}{c}\text { Semeta } \\
\text { Pembikarazn }\end{array}$ & $\begin{array}{l}\text { Himpuna } \\
\text { a Fwon }\end{array}$ & Domain \\
\hline \multirow[t]{5}{*}{1} & \multirow{5}{*}{ Inpos: } & \multirow{2}{*}{ Perminaun } & \multirow{2}{*}[51-70]{} & Rescinh & {$[51-\infty)$} \\
\hline & & & & Taggi & {$[60-\pi)$} \\
\hline & & \multirow{3}{*}{ Penxediuan } & \multirow{3}{*}[43-67]{} & Sodikn & $43-54$ \\
\hline & & & & & \\
\hline & & & & Bxyak & {$[54-69]$} \\
\hline \multirow[t]{3}{*}{2} & \multirow{3}{*}{ Ouspas } & \multirow{3}{*}{$\begin{array}{l}\text { Jumlit } \\
\text { Produlasi }\end{array}$} & \multirow{3}{*}{ [98 - 135] } & Rendah & $98-$ \\
\hline & & & & & 116] \\
\hline & & & & Thiggi & $\begin{array}{l}1116- \\
135]\end{array}$ \\
\hline
\end{tabular}

Tabel 3. Tabel Himpunan Fuzzy

\begin{tabular}{|c|c|c|c|c|c|}
\hline No & Fungd & $\begin{array}{c}\text { Nama } \\
\text { Variabel }\end{array}$ & $\begin{array}{c}\text { Semesta } \\
\text { Pembicaranan }\end{array}$ & $\begin{array}{c}\text { Himpunan } \\
\text { Fuzn }\end{array}$ & Domain \\
\hline \multirow[t]{5}{*}{$T$} & \multirow{5}{*}{ Inexa: } & \multirow[t]{2}{*}{ Permintan } & \multirow[t]{2}{*}[51-70]{} & Readah & $\begin{array}{l}51- \\
60]\end{array}$ \\
\hline & & & & Tingei & $\begin{array}{l}{[60-} \\
\gamma 0]\end{array}$ \\
\hline & & \multirow{3}{*}{ Pesediax } & \multirow{3}{*}[43-67]{} & Sedikin & $\begin{array}{l}{[43-} \\
4]\end{array}$ \\
\hline & & & & & \\
\hline & & & & Banyak & $\begin{array}{l}{[54-} \\
65]\end{array}$ \\
\hline \multirow[t]{3}{*}{2} & \multirow{3}{*}{ Oxpos } & \multirow{3}{*}{$\begin{array}{l}\text { Jumblh } \\
\text { Produlsi }\end{array}$} & \multirow{3}{*}{ [98-135] } & Rendah & $\begin{array}{l}98- \\
116\end{array}$ \\
\hline & & & & & \\
\hline & & & & Tinggi & $\begin{array}{l}{[116-} \\
135]\end{array}$ \\
\hline
\end{tabular}

Grafik Fungsi Keanggotaan Permintaan

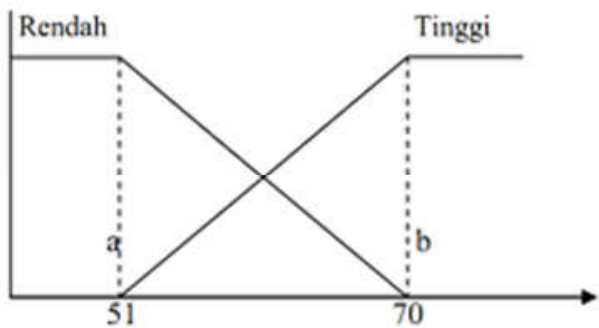




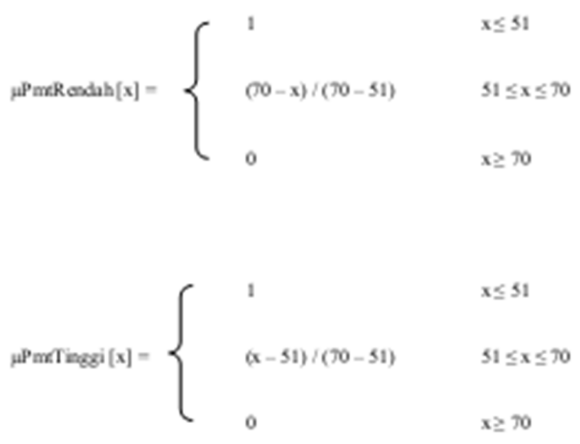

Grafik Fungsi Keanggotaan Persediaan

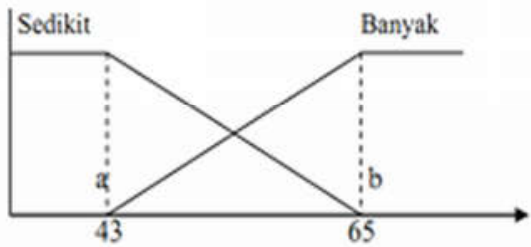

Gambar 3.21 Grafik fungsi keanggotaan persediaan

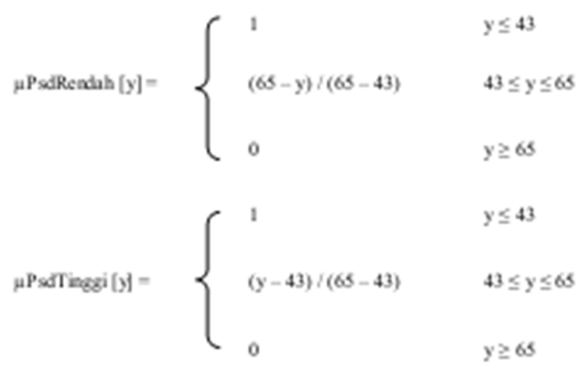

Grafik Fungsi Keanggotaan Jumlah Produksi

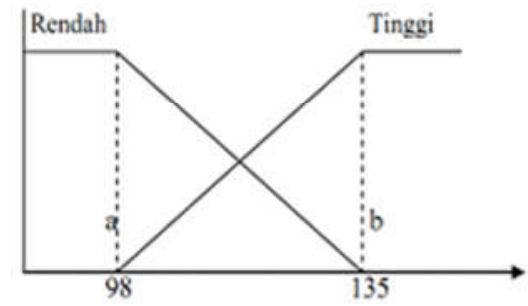

$\mu$ JpeReadid $[z]= \begin{cases}1 & z \leq 98 \\ (135-z) /(135-98) & 98 \leq z \leq 135 \\ 0 & z \geq 135\end{cases}$
$\mu$ Jpe Tingegi $[z]= \begin{cases}1 & z \leq 98 \\ (z-98) /(135-98) & 98 \leq z \leq 135 \\ 0 & z \geq 135\end{cases}$
Sementara aturan fuzzy yang digunakan adalah sebagai berikut :

1. IF Permintaan RENDAH And Persediaan SEDIKIT THEN Jumlah Produksi TINGGI;

2. IF Permintaan RENDAH And Persediaan BANYAK THEN Jumlah Produksi RENDAH;

3. IF Permintaan RENDAH And Persediaan SEDIKIT THEN Jumlah Produksi RENDAH;

4. IF Permintaan RENDAH And Persediaan BANYAK THEN Jumlah Produksi TINGGI;

5. IF Permintaan TINGGI And Persediaan SEDIKIT THEN Jumlah Produksi RENDAH;

6. IF Permintaan TINGGI And Persediaan BANYAK THEN Jumlah Produksi RENDAH;

7. IF Permintaan TINGGI And Persediaan SEDIKIT THEN Jumlah Produksi TINGGI;

8. IF Permintaan TINGGI And Persediaan BANYAK THEN Jumlah Produksi TINGGI;

Selanjutnya proses defuzifikasi yang akan menghasilkan nilai output dari perhitungan model fuzzy tsukamoto. Jumlah produksi yang akan diproduksi yaitu 118 unit.

IV. HASIL DAN PEMBAHASAN
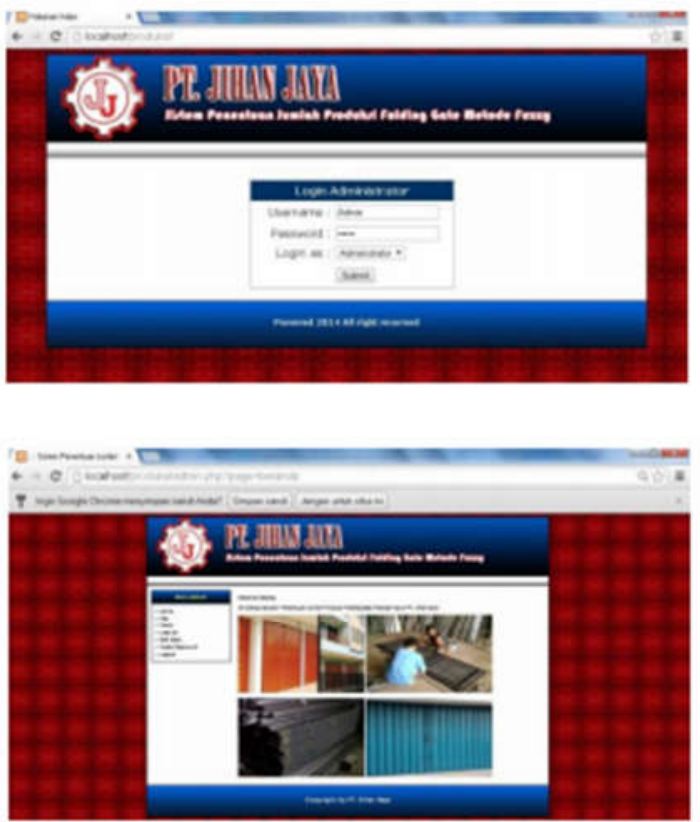

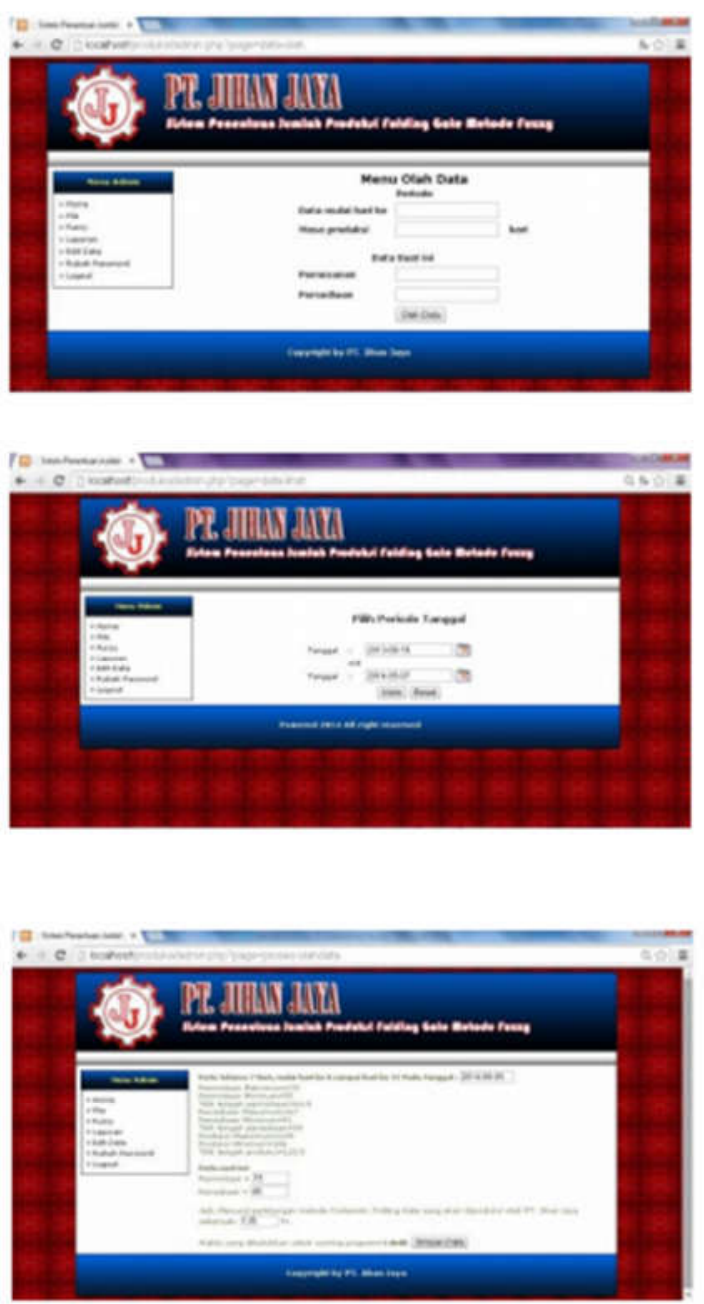

\section{HASIL DAN PEMBAHASAN}

Hasil penelitian ini telah berhasil menghitung jumlah produksi folding gate yang akurat menggunakan fuzzy logic model tsukamoto sebanyak 118 unit pada waktu selanjutnya. Penelitian ini dapat dikembangkan lagi menggunakan metode lainnya.

\section{KESIMPULAN}

Hasil penelitian ini telah berhasil menghitung jumlah produksi folding gate yang akurat menggunakan fuzzy logic model tsukamoto sebanyak 118 unit pada waktu selanjutnya. Penelitian ini dapat dikembangkan lagi menggunakan metode lainnya
VII.

[1] Al Fatta, Hanif. (2007. Analisis dan Perancanagn Sistem Informasi. Yogyakarta : ANDI. Hariyanto,

[2] Hariyanto Ir., MT. (2004). Sistem Manajemen Basisdata, Pemodelan, Perancangan dan Terapannya. Bandung : Informatika.

[3] Fathansyah. (2012). Basis Data. Bandung : Informatika. Hamdani, Haviluddin, Muhammad. (2011) "Sistem Pendukung Keputusan Pembelian Notebook Menggunakan Fuzzy Tahani." Jurnal Informatika Mulawarman. Vol. 6 No. (3). 98-104.

[4] Henderi. (2012). Perancangan Sistem Informasi. Banten : Dinas Pendidikan Provinsi Banten.

[5] Kusumadewi, Sri dan Purnomo. (2010). Aplikasi Logika Fuzzy untuk Pendukung Keputusan (Edisi 2). Yogyakarta : Graha Ilmu.

[6] Much, Eko, Fajar. (2005). "Penentuan Jumlah Produksi Dengan Aplikasi Metode Fuzzy-Mamdani.” Jurnal Ilmiah Teknik Industri. Vol. 4. No. (2). 95-04.

[7] Muisa Octavia. (2010) "Perencanaan Jumlah Produksi Meja Almunium untuk Meminimalkan Biaya Produksi Dengan Metode Fuzzy Mamdani." Skripsi pada Universitas Pembangunan Nasional "Veteran". Jawa Timur.

[8] Munawar. (2005). Pemodelan Visual dengan UML. Jakarta : Graha Ilmu. Naba, Eng Agus Dr. (2009). Belajar Cepat Fuzzy Logic Menggunakan MATLAB. Yogyakarta : Andi.

[9] Nugroho, Adi. (2005). Analisis dan Perancangan Sistem Informasi dengan Metodologi Berorientasi Objek. Bandung : Informatika.

[10] Rizky, Wahyu, Tb. Ai. (2013). "Implementasi uzzy Mamdani untuk Penentuan Pengadaan Kartu Operator pada Distributor Kartu Perdana PT. XY.” 